Dicle Tıp Dergisi / Dicle Med J (2019) 46 (1) : 33 - 39

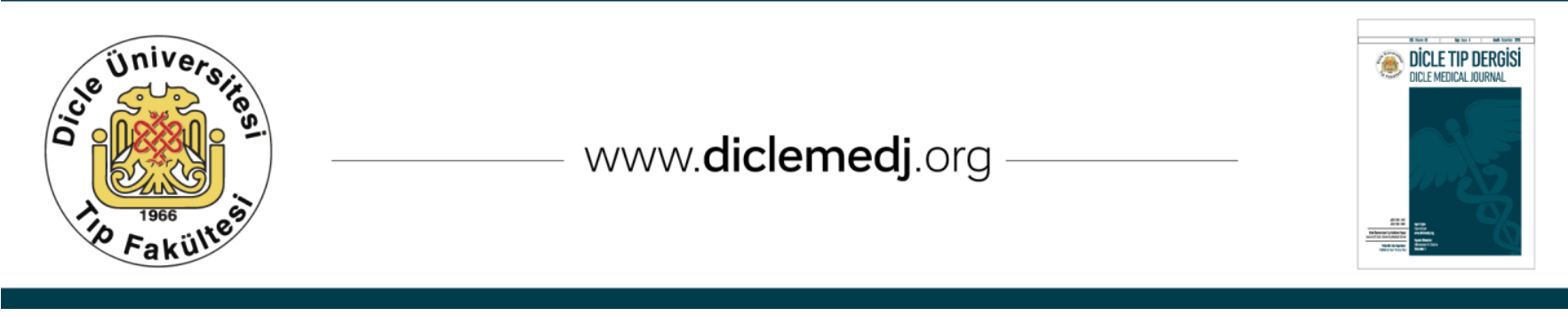

Özgün Araștırma / Original Article

\title{
Türk kadınlarında görülen saç ve saçlı deri hastalıklarının değerlendirilmesi
}

\author{
Atiye Oğrum¹, Havva Yıldız Seçkin² \\ 1 Gaziosmanpaşa Üniversitesi, Tıp Fakültesi, Deri ve Zührevi Hastalıkları Anabilim Dalı, Tokat, Türkiye ORCID: 0000-0003-2999-2691 \\ 2 Gaziosmanpaşa Üniversitesi, Tıp Fakültesi, Deri ve Zührevi Hastalıkları Anabilim Dalı, Tokat, Türkiye ORCID:0000-0002-7198-8920
}

Geliş: 21.05.2018;Revizyon: 01.09.2018;Kabul Tarihi: 16.10.2018

Öz

Amaç: Saç ve saçlı deri hastalıkları dermatoloji poliklinik başvurusunun önemli nedenlerindendir. Bu çalışmanın amacı Türk kadınlarında görülen saç ve saçlı deri hastalıklarının değerlendirilmesidir.

Yöntemler: Şubat 2015 ile Şubat 2018 yılları arasında deri ve zührevi hastalıkları polikliniğine başvuran 18 yaş üstü 16743 kadın hastaya ait dosya retrospektif olarak tarandı. Verilerde eksiklik bulunmayan 1857 kadın hasta çalıșmaya dahil edildi.

Bulgular: Bin sekiz yüz elli yedi kadın hastada $(\% 11,09)$ saç ve saçlı deri hastalığı saptandı. Hastaların yaş ortalaması $35.82 \pm 15.23$ yll (18-94 yıl) idi. Bin üç yüz yetmiş üç hasta $(\% 73,9) 45$ yaş altı, 484 hasta 45 yaş ve üzeriydi. Saptanan hastalık çeşidi sayısı 12 idi. Belirlenen toplam hastalık sayısı 1931 olup, 73 hastada $(\% 3,9)$ iki; bir hastada $(\% 0,1)$ üç farklı hastalık çeşidi mevcuttu. Skatrisyel alopesi nedeni olan hastalık oranı \%2,27 idi. En sık saptanan hastalıklar seboreik dermatit, telojen effluvium, psoriazis, alopesi areata ve androjenik alopesi idi (sırasıyla, \%43,5, \%25,4, $\% 16,4, \% 6,7$, ve $\% 4,8)$. Yaş gruplarına göre ( $<45$ yaş altı ve $\geq 45$ yaş) hastalık dağllımları değerlendirildiğinde; her iki yaş grubunda da en sık seboreik dermatit gözlenirken, bunu 45 yaş altında sırasıyla telojen effluvium ve psoriazis izlerken; 45 yaș üstünde sırayla psoriazis ve telojen effluvium takip etti. 14 kadın hastada pedikülozis mevcuttu. En sık saptanan saçlı deri hastalıkları seboreik dermatit ve psoriazis iken; en sık görülen saç hastalıkları telojen effluvium ve alopesi areata idi. En sık birliktelik gösteren hastalıklar seboreik dermatit ve telojen effluvium idi.

Sonuç: Kadınlarda dermatoloji polikliniğine başvuru nedenleri içerisinde saç ve saçlı deri hastalığının oranı \%11,09 idi. Skatrisyel alopesi ile sonuçlanan saçlı deri hastalıkları oranı ise düşüktü. Saç güzellik algısının bir parçası olduğundan, saç ve saçlı deri hastalıklarının erken tanı ve tedavisi, kişilerin özgüven ve yaşam kalitesine etkisinden dolayı önemlidir.

Anahtar kelimeler: Saç, saçlı deri, kadın, saç hastalıkları, saçlı deri hastalıkları.

DOI: $10.5798 /$ dicletip.534822

Yazışma Adresi / Correspondence: Atiye Oğrum, Gaziosmanpaşa Üniversitesi, Tıp Fakültesi, Deri ve Zührevi Hastalıkları Anabilim Dall, Tokat, Türkiye e-mail: aogrum@yahoo.com 


\title{
Evaluation of the hair and scalp diseases in Turkish women
}

\begin{abstract}
Objective: Hair and scalp diseases are an important reason for admitting to dermatology clinics. The aim of this study is to evaluate the hair and scalp diseases in Turkish women.

Methods: The records of 16743 female patients above 18 years of age, who were admitted to dermatology outpatient clinic between February 2015 and February 2018, were screened. One thousand eight hundred and fifty seven female patients having hair and scalp diseases, without any missing information, were included in the study.

Results: One thousand eight hundred and fifty seven female patients (\%11.09) had hair and scalp diseases. The mean age of patients were $35.82 \pm 15.23$ years (18-94 years). One thousand three hundred and seventy three patients (73.9\%) were under 45 years of age; 484 patients were above 45 years of age.There were 12 types of hair and scalp diseases. The total number of diseases was 1931 and, there were two types of diseases in 73 patients (3.9\%) and three types in one patient $(0.1 \%)$. Disease rate that cause the cicatricial alopecia was $\% 2.27$. Seborrheic dermatitis, telogen effluvium, psoriasis, alopecia areata, and androgenic alopecia were the most common diseases (43.5\%, 25.4\%, $16.4 \%, 6.7 \%$, and $4.8 \%$, respectively). When diseases were evaluated according to age groups $(<45$ years and $\geq 45$ years), the most common disease were seborrheic dermatitis in both groups, followed by telogen effluvium and psoriasis in group of under 45 years of age; psoriasis and telogen effluvium in group of above 45 years of age. Fourteen female patients had pediculosis. The most common scalp diseases were seborrheic dermatitis and psoriasis; hair diseases were telogen effluvium and alopecia areata. The most common associated diseases were seborrheic dermatitis and telogen effluvium.
\end{abstract}

Conclusion: The rate of hair and scalp diseases among women admitted to the dermatology clinic was $11.09 \%$. However, the rate of the scalp diseases resulted in cicatrial alopecia were low. Hair is a component of beauty perception, so earyl diagnosis and treatment of hair and scalp diseases are important for impact on both self-esteem and quality of life.

Keywords: Hair, scalp, woman, hair diseases, hair and scalp diseases.

\section{GİRiş}

Saç, özellikle kadınlarda, güzellik algısının önemli bir parçasıdır. Saç sağlı̆̆ı, saçı besleyen ve destekleyen saçlı derinin sağlığıyla ilişkilidir. Saç ve saçlı deriyi etkileyen hastalıklar, bu alana lokalize hastalıklar nedeniyle olabileceği gibi, dermatolojik hastalıkların saçlı deri tutulumuna sekonder ya da sistemik nedenlerle ilişkili olarak ortaya çıkabilir. Klinik tablo, hastalığın şiddeti ya da etiyolojisine bağlı olarak skatrisyel ya da nonskatrisyel alopesiyle sonuçlanabilir. $\mathrm{Bu}$ durum kişinin özgüven problemi yaşamasına neden olup, yaşam kalitesini süreli ya da süresiz olarak olumsuz yönde etkileyebilir ${ }^{1}$. Saç ve saçlı deri hastalık prevalans ve spektrumu etnik gruplara göre farklıllk göstermekte olup, buna yönelik literatür bilgisi sınırlıdır2,3. Bu çalışmanın amacı, Türk kadınlarındaki saç ve saçlı deriyi etkileyen hastalıkların prevalans ve spektrumunu ve bu konudaki olası etnik farklılıkları değerlendirmektir.

\section{YÖNTEMLER}

18-KAEK-071 nolu etik kurul onayı sonrası, Şubat 2015 ile Şubat 2018 yılları arasında Gaziosmanpaşa Üniversitesi Tıp Fakültesi deri ve zührevi hastalıkları polikliniğine başvuran 18 yaş üstü 16743 kadın hastaya ait dosya retrospektif olarak tarandı. Verilerde eksiklik olmayan ve saç ve saçlı deri hastalığı tanısı alan 1857 kadın hasta çalışmaya dahil edildi. Hastaların demografik özellikleri kaydedildi ve hastalar yaşlarına göre 18-44 yaş arası ve 45 yaş ve üstü olmak üzere 2 grupta incelendi.

Sayısal veriler ortalama ve standart sapma olarak, kategorik veriler ise sayı ve yüzde olarak gösterildi. Veriler Statistical Package for 
Social Sciences (SPSS Inc.,Chi, IL) programı versiyon 20 programı ile analiz edildi. Tüm analizlerde istatistik anlamlılık $\mathrm{p}<0.05$ olarak kabul edildi.

\section{BULGULAR}

Değerlendirmeye alınan 16743 kadın hasta dosyasının 1857'sinde (\%11,09) saç ve saçlı deri hastalığı saptandı. Hastaların yaşları 18-94 yıl arasında değişmekte olup, yaş ortalaması $35.82 \pm 15.23$ idi. Hastaların 1373'ü $(\% 73,9) 45$ yaş altı, 484'ü $(\% 26,1) 45$ yaş ve üzeriydi. Saptanan hastalık çeşidi sayısı 12 idi. Belirlenen toplam hastalık sayısı 1931 olup, 73 hastada $(\% 3,9)$ iki; bir hastada $(\% 0,1)$ üç farklı hastalık türü mevcuttu. Hastaların 1848'inde $(\% 99,5)$ klinik muayene ile; 25 'inde $(\% 0,5)$ (üç izole saçlı deri psoriazisi, 12 liken planoplaris ve 10 diskoid lupus eritematozus olgusu) ek histopatolojik inceleme ile tanıya ulaşıldığı saptandı. En sık saptanan hastalıklar sıklık sırasına göre; seboreik dermatit, telojen effluvium, psoriazis, alopesi areata ve androjenik alopesi idi. Yaş gruplarına göre $(<45$ yaş altı ve $\geq 45$ yaş) hastalık dağılımları değerlendirildiğinde, her iki yaş grubunda da en sık seboreik dermatit gözlenirken, bunu 45 yaş altında sırasıyla telojen effluvium ve psoriazis takip ederken; 45 yaş üstünde sırayla psoriazis ve telojen effluvium takip etmekteydi. Pseudopelad ve frontal fibrozan alopesi tanisı alan hastaların tamamı 45 yaş ve üzeri iken; pedikülozis tanısı alan 14 hastanın 13'ü 45 yaş altı idi. Hastalıkların yaş gruplarına göre dağılımı tablo I'de özetlendi.

Hastalık birliktelikleri değerlendirildiğinde, en sık birliktelik gözlenen hastalık seboreik dermatit ve telojen effluvium idi. Saç ve saçlı deri hastalıklarının birliktelik durumları tablo II'de özetlendi.

Hastalıkların klinik tipleri değerlendirildiğinde, saçlı deri tutulumu olan psoriazis hastalarının altısı püstüler, altısı guttat, yedisi izole saçlı deri psoriazisi iken; kalan 299 hasta kronik plak tip psoriazis idi. Alopesi areatalı hastaların dördünde alopesi totalis, ikisinde alopesi üniversalis kliniği mevcuttu. Liken planoplaris tanılı 14 hastanın ikisinde saçlı deri lezyonlarına gövdede liken planus lezyonu eşlik etmekteydi.

Hastalıklar skatrisyel ve nonskatrisyel alopesi yapma durumuna göre gruplandırıldığında, 44 hastada $(\% 2,36)$ skatrisyel alopesi yapan hastalık olduğu gözlendi.

Tablo 1: Saç ve saçlı deri hastalıklarının yaş gruplarına göre dağılımı

\begin{tabular}{|l|c|c|c|}
\hline \multirow{2}{*}{ Hastalık adı } & \multicolumn{2}{|c|}{ Hastalık Sayısı n (\%) } & \multirow{2}{*}{ Toplam (\%) } \\
\cline { 2 - 3 } & $\mathbf{4 5}$ yaş altı & $\begin{array}{c}\mathbf{4 5} \text { yaş ve } \\
\text { üzeri }\end{array}$ & \\
\hline Seboreik dermatit & $617(31,9)$ & $224(11,6)$ & $841(43,5)$ \\
\hline Telojeneffluvium & $436(22,5)$ & $55(2,8)$ & $491(25,4)$ \\
\hline Psoriazis & $171(8,8)$ & $147(7,6)$ & $318(16,4)$ \\
\hline Alopesiareata & $107(5,5)$ & $23(1,2)$ & $130(6,7)$ \\
\hline Androjenikalopesi & $77(4)$ & $16(0,9)$ & $93(4,8)$ \\
\hline Pedikülozis & $13(0,67)$ & $1(0,05)$ & $14(0,7)$ \\
\hline Liken planoplaris* & $7(0,4)$ & $7(0,4)$ & $14(0,7)$ \\
\hline Diskoidlupuseritematozus* & $1(0,05)$ & $9(0,5)$ & $10(0,5)$ \\
\hline Trikotillomani* & $6(0,3)$ & $3(0,2)$ & $9(0,5)$ \\
\hline Frontalfibrozanalopesi* & - & $7(0,4)$ & $7(0,4)$ \\
\hline Folikülitisdekalvans* & $1(0,05)$ & $2(0,2)$ & $3(0,2)$ \\
\hline Pseudopelad* & - & $1(0,05)$ & $1(0,05)$ \\
\hline Toplam & 1436 & $\mathbf{4 9 5}$ & 1931 \\
\hline
\end{tabular}

*Skatrisyel alopesi nedeni olan hastalık

\section{TARTIŞMA}

Saç, güzellik algısının önemli bir aksesuarı olduğundan, saç ve saçlı derinin sağlığl, özellikle kadınlar için önem arz eder. Bu hastalıklar, neden olduğu kaşıntı gibi semptomlar ve oluşturduğu kozmetik kaygı nedeniyle, kişiyi hem fiziksel hem de psikolojik yönden etkileyebilir. Bilgiç ve $\operatorname{ark}^{4}$ üçüncü basamak bir sağlık kuruluşunun saç hastalıkları ünitesine başvuran hastaları değerlendirdikleri retrospektif çalışmalarında, saç hastalıklarının 
poliklinik başvuru sayısı içerisindeki oranını \%7 olarak bildirmiştir, ancak çalışmalarında erkek ve kadınlardaki başvuru oranına dair bir değerlendirme yapılmamıştır. Bu çalışmada dermatoloji polikliniğine başvuran kadın hastaların \%11,09'unda saç veya saçlı deriyi ilgilendiren hastalık saptanmış olup, bu oranın bu grup hastalıkların önem düzeyini gösterir nitelikte olduğunu düşünüyoruz.

Tablo 2: Saç ve saçlı deri hastalıklarının birliktelik durumları

\begin{tabular}{|l|c|c|c|c|c|c|c|}
\hline & Yok & $\begin{array}{c}\text { Androjenik } \\
\text { alopesi }\end{array}$ & $\begin{array}{c}\text { Trikotillo } \\
\text { mani }\end{array}$ & $\begin{array}{c}\text { Seboreik } \\
\text { dermatit }\end{array}$ & $\begin{array}{c}\text { Telojen } \\
\text { effluvium }\end{array}$ & $\begin{array}{c}\text { Alopesi } \\
\text { areata }\end{array}$ & Toplam \\
\hline Seboreik dermatit & 788 & 2 & 1 & - & 23 & - & 814 \\
\hline Telojen effluvium & 435 & 3 & - & 18 & - & 1 & 457 \\
\hline Psoriazis & 314 & - & - & - & 2 & 2 & 318 \\
\hline Alopesi areata & 118 & - & - & 1 & 6 & - & 125 \\
\hline Androjenik alopesi & 75 & - & - & 6 & 3 & 2 & 86 \\
\hline Pedikülozis & 12 & 1 & - & 1 & - & - & 14 \\
\hline Liken planoplaris & 14 & - & - & - & - & - & 14 \\
\hline Diskoid lupus eritematozus & 10 & - & - & - & - & - & 10 \\
\hline Trikotillomani & 7 & - & - & 1 & - & - & 8 \\
\hline Frontal fibrozan alopesi & 7 & - & - & - & - & - & 7 \\
\hline Folikülitis dekalvans & 3 & - & - & - & - & - & 3 \\
\hline Pseudopelad & 1 & - & - & - & - & - & 1 \\
\hline Toplam & 1784 & 6 & 1 & 27 & 34 & 5 & 1857 \\
\hline
\end{tabular}

* ilk müracatta alınan tek tanı ya da ana tanı

** Sonraki müracatta alınan tanı ya da ilk müracatta alınan ek tanı

Saç dökülmesi kıl folikülünün kalıcı hasarına sekonder skatrisyel ya da geri dönüşümlü hasara sekonder nonskatrisyel formda olabilir, ayrıca yaygınlığına göre lokalize ya da diffüz paternde ortaya çlkabilirr ${ }^{5,6}$. Bilgiç ve ark nın ${ }^{4}$ çalışmasında hastaların \%6'sında skatrisyel alopesi saptandığı ve bunların 2/3'ünün kadın olduğu bildirilmiştir. Çalışmamızda uzun dönemde skatrisyel alopesi riski bulunan trikotillomani de dahil edildiğinde, 44 kadında $(\% 2,36)$ skatrisyel alopesi gözlenmiş olup, diğer çalışmaya kıyasla oranın düşük olması, çalışmaya dahil edilen/edilmeyen hastalık gruplarındaki farklılıktan kaynaklanabilir.
Skatrisyel alopesi nedeni olan hastalıkların, tüm saç ve saçlı deri hastalıkları içerisindeki oranı düşük olmakla birlikte, tablonun tıbbi tedaviye rağmen düzelmemesi, progresyonun durdurulmasında tüm hastalarda etkinliği kanıtlanmış bir tedavi metodunun olmayışı, ilerlemenin durdurulması için erken tanı ve müdahalenin zorunluluğu ve oluşturduğu psikolojik yıkım nedeniyle skatrisyel alopesi nedeni olan hastalıkların erken teşhis ve tedavisi önem arzeder.

Saç ve saçlı deri hastalıkları içerisinde en yüksek oranda saptanan seboreik dermatit, etnik farklılıklar gösterebilmekle birlikte, 
toplumun \%2-8'ini etkiler7. Bununla birlikte adölesan erkek ya da ileri yaş gibi seçilmiş gruplarla yapılan prospektif çalışmalarda \%23 gibi yüksek oranlar bildirilmiştir ${ }^{8-10}$. Ayrıca, obezite, açık ten rengi, depresyon, hipertansiyon, HIV enfeksiyonu, Parkinson hastalığı, kış mevsimi, jeneralize kserozis kutis, yüksek eğitim seviyesi, alkol ve sigara kullanımının seboreik dermatitle ilişkisini bildiren çalışmalar mevcuttur ${ }^{10-12}$. Çalışmamızda kadınlarda saptanan seboreik dermatit prevalansı \%5,02 olup literatürle uyumluydu, bununla birlikte, 45 yaş sınır olarak alındığında, 45 yaş altı ve üstünde hastalığın görülme oranı benzerdi. Güler Özden ve ark nın ${ }^{13}$ yaygın saç kaybıyla giden dermatolojik hastalıkları değerlendirdiği çalışmalarında, yaygın saç kaybına en sık eşlik eden dermatolojik hastalık seboreik dermatit olarak bildirilmiştir. Çalışmamızda seboreik dermatitin en sık görülen saçlı deri hastalığı olmasının, toplumda yüksek oranda görülmesine ek olarak, neden olduğu kepeklenme ve kaşıntı gibi semptomlar ve eşlik eden saç dökülmesi nedeniyle, hastaların sağlık kuruluşuna başvurma ihtiyacı duymasıyla ilgili olabileceğini düşünüyoruz.

Telojen effluvium, kadınlarda diffüz saç kaybının en sık nedenidir ${ }^{14}$. Hastalık akut (altı aydan kısa süreli) ya da kronik (altı aydan uzun süren) formda ortaya çıkabilir. Gerçek insidans ve prevalansı bilinmemekle birlikte, hastalığın 21-40 yaş aralığında pik yaptığı bildirilmiștir ${ }^{15}$. $\mathrm{Bu}$ çalışmada, kadınlarda telojen effluvium prevalansı \%2,93 olarak saptanmış olup, literatürle uyumlu olarak telojen effluvium tanılı kadınların \%88,7'si 45 yaş altında idi. Ayrıca telojen effluviumla en sik birliktelik gösteren saçlı deri hastalığının seboreik dermatit olduğu saptanmış olup, bu birliktelik Güler ve ark nın ${ }^{13}$ çalışmasında da bildirilmiștir. Doğum, malnütrisyon, hastalıklar, emosyonel stres, ilaçlar, majör cerrahi operasyon veya kıl folikül döngüsünü bozan diğer metabolik olaylar hastalıkta tetikleyici rol oynayabilir ${ }^{16}$ Hastaların 1/3'ünde araştırmalara rağmen etiyolojik neden saptanamaz. Tetikleyici olaydan yaklaşık 2-3 ay sonra ortaya çıkan diffüz saç kaybıyla karakterize olup, sıklıkla ani ve şiddetli saç dökülmesi nedeniyle hastada anksiyeteye neden olur ${ }^{17}$.

Üçüncü sıklıkta saptanan psoriazis, kronik inflamatuvar bir deri hastalığ görülen formu kronik plak tiptir ${ }^{18}$. Psoriazis hastalarının \%79'unda saçlı deri tutulumunun olduğu bildirilmiş olup, saçlı deri en sık tutulan alanlardandır ${ }^{19}$. Saçlı deri psoriazisi neden olduğu semptom ve klinikle kişide fiziksel rahatsızlık ve emosyonel strese neden olabilir ${ }^{20}$. İzole saçlı deri psoriazisi formu nadir olup, bu çalışmada yedi hastada izole form saptandı ve seboreik dermatitten sonra ikinci sıklıkta saptanan saçlı deri hastalığı idi. Her iki hastalık da saçlı deride oluşturduğu semptom ve klinik görünümle bireylerde anksiyeteye neden olabilir ve yaşam kalitesini olumsuz etkileyebilir.

Alopesi areata, ani ve skarsız kıl kaybıyla karakterize olan organ spesifik otoimmün kıl folikülü hastalığıdır ${ }^{21}$. Toplumun $\% 0,1-2,1$ 'ini etkileyen hastalık, her yaşta gözlenmekle birlikte en sık ilk üç dekatta görülür ${ }^{22,23}$. Bu çalışmada kadınlardaki alopesi areata prevalansı \%0,7 olarak saptanmış olup, literatürle uyumluydu. Ayrıca hastaların yaş aralığı 15-66 yıl olmakla birlikte, alopesi areata tanılı hastaların \%82'si 45 yaş altı idi. Geç başlangıçlı form daha nadir görülmekte olup, 50 yaş ve üzeri başlangıç gösteren alopesi areata olgularının değerlendirildiği bir çalışmada, bu formda kadın predominansının belirgin olduğu, kliniğin daha sınırlı ve tam düzelme oranının daha yüksek olduğu bildirilmiştir ${ }^{24}$. Klinik olarak oval alopesik yamalarla karakterize olmakla birlikte, tüm saçlı derinin tutulduğu alopesi totalis ya da tüm vücut kıllarının tutulduğu alopesi üniversalis formunda da görülebilir ${ }^{25}$. Bu çalışmada da dört hastada alopesi totalis, iki hastada alopesi 
üniversalis kliniği mevcuttu. Çalışmamızda saç ve saçlı deri hastalıkları ayrı kategoriler halinde değerlendirildiğinde, alopesi areatanın en sık saptanan ikinci saç hastalığı olduğu değerlendirilebilir. Skar oluşturmamakla birlikte, kadınlarda görülen saç hastalıkları içindeki oranı, rekürren ataklarla seyredebilmesi, hastalık seyrine ilişkin öngörü yapılamaması ve oluşturduğu kozmetik kaygı nedeniyle, kadınlarda görülen saç hastalıkları içerisinde önemli bir grubu oluşturduğunu düşünüyoruz.

Pedikülozis kapitis, Pediculus humanus capitis ektoparazitinin saçlı deride yerleșimi sonucu ortaya çıkan bir enfestasyondur ${ }^{26}$. Her yaş grubunu etkilemekle birlikte, en sık 3-12 yaş aralığındaki kızlarda görülür. Bu çalışmada 14 kadın hastada pedikülozis saptanmakla birlikte, çocuklarda gerek sağlık taramalarıyla, gerekse saçı kaşınan çocuğun ebeveyn tarafından muayenesiyle daha kolay tanı konulduğunu ve ebeveynlerin bir bölümünün de bu yolla tanı almadan tedavi edildiğini, bu nedenle kadınlardaki gerçek pedikülozis oranının saptanandan daha yüksek olduğunu düşünüyoruz.

\section{Kısıtlılıklar}

$\mathrm{Bu}$ çalışmada bazı kısıtlılıklar mevcuttur. Öncelikle çalışma retrospektif dizaynda olduğundan dosya verilerinde eksiklik olan saç ve saçlı deri hastalığı tanılı olgular çalışmaya dahil edilememiştir. İkinci olarak saç ve saçlı deriyi tutan hastalık spektrumu oldukça geniş olduğundan, bu çalışmada değerlendirmeye alınan hastalık grupları diğer çalışmalara kıyasla farklılık gösterebilir. Bunun yanısıra çalışmaya dahil edilen hasta grubu bir üniversite hastanesinin dermatoloji polikliniğine müracat eden hastalardan oluştuğundan sonuçlar genellenemez.

\section{SONUÇ}

Kadınlarda dermatoloji polikliniğine başvuru nedenleri içerisinde saç ve saçlı deri hastalığının oranı oldukça yüksekti. En sık saptanan saçlı deriyi tutan hastalıklar seboreik dermatit ve psoriazis iken; en sık saptanan saç hastalıkları telojen effluvium ve alopesiareata idi. Skatrisyel alopesi nedeni olan hastalıkların grup içerisindeki oranı düşük olmakla birlikte, oluşan hasarı düzeltme ve önleme konusunda etkin tedavi yetersizliği nedeniyle, hastalıklar içerisinde önemli bir grubu oluşturur. Saç ve saçlı deri hastalıkları neden olduğu semptom ve hastanın fiziksel özelliğinde yaptığı değişiklikler nedeniyle, kişinin yaşam kalitesini süreli ya da süresiz olarak olumsuz yönde etkileyebilir, bu nedenle bu hastalıkların erken tanı ve etkin tedavisi önem arz eder.

Çıkar Çatışması Beyanı: Yazarlar çıkar çatışması olmadığını bildirmişlerdir.

Finansal Destek: Bu çalıșma her hangi bir fon tarafından desteklenmemiştir.

Declaration of ConflictingInterests:The authors declare that they have no conflict of interest.

Financial Disclosure: No financial support was received.

\section{KAYNAKLAR}

1. Tosti A, Gray J. Assessment of hair and scalp disorders. J Investig Dermatol Symp Proc 2007; 12: 23-7.

2. Rodney IJ, Onwudiwe OC, Callender VD, et all. Hair and scalp disorders in ethnic populations. J Drugs Dermatol 2013; 12: 420-7.

3. Lindsey SF, Tosti A. Ethnic hair disorders. Curr Probl Dermatol 2015; 47: 139-49.

4. Bilgiç Temel A, Şenol Y, Nazlım B, ve ark. Saç hastalıkları ünitesi deneyimi: 1617 olgunun analizi. Turk J Dermatol 2016; 10: 19-26.

5. Karakuzu A. Primer sikatrisyel alopesiler. Türkderm 2014; 48: Özel Sayı1: 56-9.

6. Aldemir S, Erpolat S, Dalbudak E, ve ark. Diffüz alopesili kadınlarda öfke, anksiyete ve depresyon. Dicle Tip Derg 2015; 42: 335-41. 
7. Palamaras I, Kyriakis KP, Stavrianeas NG. Seborrheic dermatitis: lifetime detection rates. J Eur Acad Dermatol Venereol 2012; 26: 524-6.

8. Breunig J de A, de Almeida HL Jr, Duquia RP, et all. Scalp seborrheic dermatitis: prevalence and associated factors in male adolescents. Int J Dermatol 2012; 51: 46-9.

9. Mastrolonardo M, Diaferio A, Vendemiale G, et all. Seborrhoeic dermatitis in the elderly: inferences on the possible role of disability and loss of self-sufficiency. Acta Derm Venereol 2004; 84: 285-7.

10. Sanders MGH, Pardo LM, Franco OH, et all. Prevalence and determinants of seborrhoeic dermatitis in a middle-aged and elderly population: the Rotterdam Study. Br J Dermatol 2018; 178: 148-53.

11. Gupta AK, Bluhm R, Cooper EA, et all. Seborrheic dermatitis. Dermatol Clin 2003; 21: 401-12.

12. Linder D, Dreiher J, Zampetti A, et all. Seborrheic dermatitis and hypertension in adults: a cross-sectional study. J Eur Acad Dermatol Venereol 2014; 28: 1450-5.

13. Güler ÖM, Öztaş MO, Gülekon A, ve ark. Kadın olgularda yaygın saç kaybı ve eşlik eden bulgular. Ondokuz Mayıs Üniversitesi Tıp Dergisi 2008; 25: 50-6.

14. Malkud S. Telogen Effluvium: A Review. J Clin Diagn Res 2015; 9: WE01-3.

15. Fatani MI, Bin mahfoz AM, Mahdi AH, et all. Prevalence and factors associated with telogen effluvium in adult females at Makkah region, Saudi Arabia: A retrospective study. J Dermatol Dermatol Surg 2015; 19: 27-30.

16. Shrivastava SB. Diffuse hair loss in an adult female: Approach to diagnosis and management. Indian J Dermatol Venereol Leprol 2009; 75: 20-8.
17. Çetinkünar D, Önder M. Telojen efluviyum. Turkiye Klinikleri J Dermatol 2011; 21: 140-51.

18. Biçer A, Basar N, Karasu BB, ve ark. Psöriazis hastalarında artmıs QT dispersiyonu. Dicle Tıp Derg 2010; 37: 223-7.

19. Kerkhof PCM van de, Steegers-Theunissen RPM, Kuipers MV. Evaluation of topical drug treatment in psoriasis. Dermatology 1998; 197: 31-6.

20. Poyner TF, Fell PJ. Frequency of patients with plaque psoriasis who had not consulted their doctor in the past year. Br J ClinRes 1995; 6: 201-7.

21. Oğrum A, Boyraz N, Karataș Toğral A, ve ark. Alopesi areatalı hastalarda 25 hidroksi vitamin D3 düzeyinin değerlendirilmesi. Türkderm 2015; 49: 50-3.

22. Mirzoyev SA, Schrum AG, Davis MDP, et all. Lifetime incidence risk of alopecia areata estimated at $2.1 \%$ by Rochester Epidemiology Project, 1990-2009. J Invest Dermatol 2014; 34: 1141-2.

23. Kavak A, Yesildal N, Parlak AH, et all. Alopecia areata in Turkey: demographic and clinical features. J Eur Acad Dermatol Venereol 2008; 22: 977-81.

24. Lyakhovitsky A, Gilboa S, Eshkol A, et all. Late-onset alopecia areata: A retrospective cohort study. Dermatology 2017; 233: 289-94.

25. Polat M, Parlak AH, Şereflican B. Dermatoloji kliniğinde görülen alopesi areatalı hastaların klinik ve epidemiyolojik özellikleri. Göztepe Tıp Dergisi 2010; 25: 86-90.

26. Takcı Z, Tekin O, Karadag AS. Pediculid case: autosensitization dermatitis caused by pediculosis capitis. Turkiye Parazitol Derg. 2012; 36: 185-7. 